\title{
A SIMULATION-BASED APPROACH FOR ESTIMATING RAILWAY CAPACITY
}

\author{
LUCA D'ACIERNO, MARILISA BOTTE \& GIUSEPPE PIGNATIELLO \\ Department of Civil, Architectural and Environmental Engineering, \\ Federico II University of Naples, Italy
}

\begin{abstract}
The article proposes a simulation-based approach for supporting a threshold analysis aimed at identifying the maximum number of trains to be operated on a line, given the related infrastructural and operational constraints. The method addresses an intermediate case between the theoretical and practical capacity conditions (i.e. simulated capacity). Moreover, the evaluated capacity represents an upper-bound value and, therefore, it is independent of the involved demand flows which, hence, have been neglected in the provided discussion. In particular, against an initial effort for building the rail micro-simulation model, which requires the modelling of infrastructure layout, signalling system, rolling stock and planned timetable, the presented methodology allows infrastructure managers to properly direct the decision-making process by providing information on the effects of any intervention, in advance of its effective implementation. In order to show the feasibility and usefulness of the proposed approach, it has been applied in the case of a real rail network context in the south of Italy.

Keywords: Railway systems, rail simulation models, railway capacity estimation, threshold analysis, timetabling design process.
\end{abstract}

\section{INTRODUCTION}

The properties of sustainability and efficiency which railway systems offer make them a key transport option in a context affected by congestion and pollution issues. Indeed, in the literature, several matters related to the management and optimisation of metro/rail networks have been addressed, such as timetabling and rescheduling tasks [1-5], the interactions with travel demand [6-12], the implementation of energy-saving policies ([13-17] and the impacts on the territories [18-21].

The timetabling process of a railway line consists in establishing the departure and arrival times of each convoy at each station being served, respecting the limits imposed by safety, law, infrastructure, signalling system and the necessity to guarantee a certain number of transfers. Such a planning phase is crucial for the entire railway operation as it influences, directly or indirectly, system performance, the degree of use of the infrastructure capacity, service quality, the management of rolling stock and the crew scheduling. While, at the operational level, rescheduling tasks are aimed at properly reacting to system failure and re-establishing ordinary service conditions as rapidly as possible, so as to minimise the inconvenience. In particular, as shown by [22], it is possible to distinguish between disturbance and disruption: disturbances are generally considered as small perturbations influencing the system; while, disruptions indicate large external incidents which can lead to the cancellation of runs within the timetable or even to the interruption of the whole service. Clearly, the greater the severity of the failure, the greater the impact of the corrective measures to be adopted.

Rail transport, just as any other transport system, is not finalised to itself, but its task is to move people or goods around, and, therefore, a realistic and accurate analysis cannot ignore passenger/freight flows features. In this context, [23] provides an analysis of the rail system in the European framework where different network layouts are linked to a set of key parameters affecting the rail service and the main cost drivers are critically discussed. Hence, the 
time-spatial distribution of involved demand flows needs to be evaluated and, for instance, the behaviour of passengers in the different phases of the trip (turnstile access, transfer from the turnstiles to the platform, waiting on platform, boarding and alighting process, etc.) needs to be accurately modelled. In particular, as shown by [24], a key issue to be addressed is the dynamic interaction between passengers and rail service at the interface train-platform. Finally, transport modes based on railway technology present a favourable ratio between operational costs (including energy consumption) and transport capacity with respect to other mobility systems. Therefore, in order to maximise such energy efficiency, several eco-driving measures [25-28] and energy-recovery strategies [29-31] have been proposed.

This article, instead, deals with capacity issues related to the degree of infrastructural utilisation in railway contexts. The concept of capacity is rather articulate to be addressed, since it can be considered by different perspectives. First, as shown by [32], it is necessary to make a distinction between theoretical capacity and practical capacity. The theoretical capacity of a line is the number of trains that can circulate in a specific time interval assuming minimum distancing values between trains and the absence of disturbances. It represents the upper limit as it describes the ideal operating conditions, ignoring the effects caused by eventual unforeseen events or disturbances that occur in reality. Practical capacity is the actual limit of the volume of traffic that can be managed on a line or in a node at certain levels of regularity, reflecting the actual heterogeneous composition of traffic. However, an intermediate condition can be identified, which represents the maximum number of trains to be operated in a line, not in ideal conditions, but considering a series of operational constraints such as buffer times, inversion manoeuvres and terminal stations organisation. From this point forward, this kind of capacity is referred to as simulated capacity.

Moreover, as shown by [33], capacity is based on the relations between the following parameters:

- The number of trains. In fact, the more trains are, the less capacity is left for traffic quality;

- The average speed. The braking distance increases proportionally more than the average speed;

- The stability. In order to avoid the propagation of minor delays, margins and buffers have to be added to the running time of trains and between paths;

- The heterogeneity. The more are the differences between the train running times, the more capacity will be consumed.

The relation between these parameters is shown in the so-called capacity balance depicted in Fig. 1. As can be seen, a chord links the points on the axes, expressing the value for each parameter, and the length of the chord corresponds to the capacity. The capacity utilisation is then defined by the positions of the chord on the four axes.

As said, capacity can be viewed differently according to the subject considered. Indeed, while from a market point of view capacity demands are oriented to satisfy peak values, infrastructure planning is interested in a definition of capacity which guarantees a profitable utilisation of the infrastructure. From a timetable standpoint, by contrast, capacity considerations are necessary to define train paths trying to fulfil travel demand needs on a given infrastructure. Finally, from an operational point of view, capacity evolves continuously and depends on current infrastructure availability, delays, diversion and number of additional trains.

In this framework, our goal is to perform a preliminary threshold analysis providing the upper bound of the number of trains that can be operated on a line, given infrastructural and operational constraints (i.e. simulated capacity). Such an evaluation is clearly independent of 


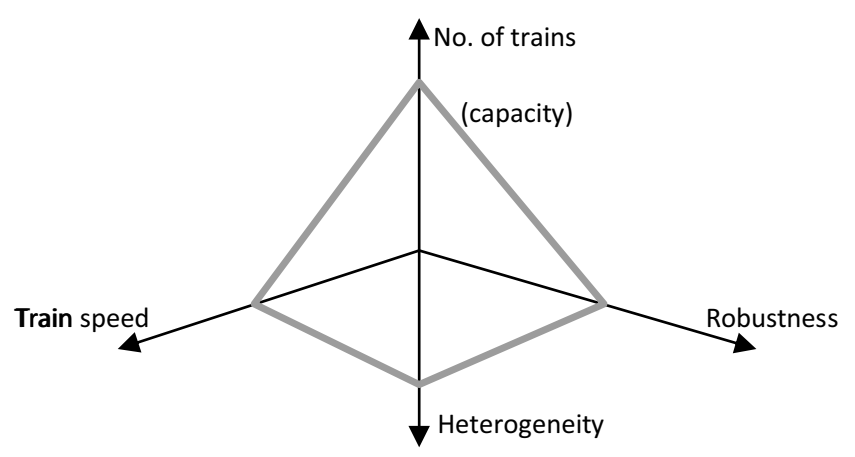

Figure 1: Capacity balance [33].

the number of passengers who effectively use the analysed rail services and, for this reason, although the importance of considering involved demand flows stated above, they have been neglected in the provided discussion.

According to the literature, three main approaches can be identified for estimating railway capacity: (i) analytical methods [34-38]; (ii) optimisation methods [33, 39] and (iii) simulation methods [32, 40]. In particular, simulation models can be classified based on different criteria. First, according to the assumption on the level of detail considered for the network representation, it is possible to have macroscopic [41, 42], mesoscopic [43, 44] and microscopic $[45,46]$ simulation models. Moreover, based on the assumption made on the involved variables, it is possible distinguishing deterministic [47, 48] and stochastic [49, 50] models. The deterministic case deals with parameters characterised by a steady value equal to their average; on the other hand, in the case of stochastic simulations, involved parameters are considered as random variables and, therefore, they are modelled by means of their probability density function $(p d f)$, as well as the mean and the standard deviation of the pdf itself. Finally, according to the adopted processing techniques, we can have synchronous [51, 52] and asynchronous [53] simulation models. In particular, synchronous approaches simulate the events as they occur in reality; therefore, a chronological progression is followed, with no chance of returning to previous states. In asynchronous models, on the other hand, the convoys are simulated according to their class of priority. Specifically, we adopted a what-if design method, based on a microscopic model of the railway infrastructure; while, the simulation of rail service follows a deterministic/synchronous approach.

The remainder of the article is structured as follows: Section 2 outlines the provided methodology for estimating the maximum performance of the network in terms of simulated capacity; Section 3 presents an application of the proposed approach in the case of a real rail line; finally, Section 4 summarises conclusions and research prospects.

\section{THE PROPOSED METHODOLOGY}

The proposed approach (described in Fig. 2) represents a simulation-based method aimed to perform a preliminary evaluation on the maximum performance of a railway network in terms of number of trains that can be operated on a given line, so as to carry out a threshold analysis of the available potentiality. In particular, we proposed a what-if methodology consisting in identifying a certain set of scenarios to be modelled and tested, thus evaluating the related performance indexes and selecting the best option according to the target pursued. 


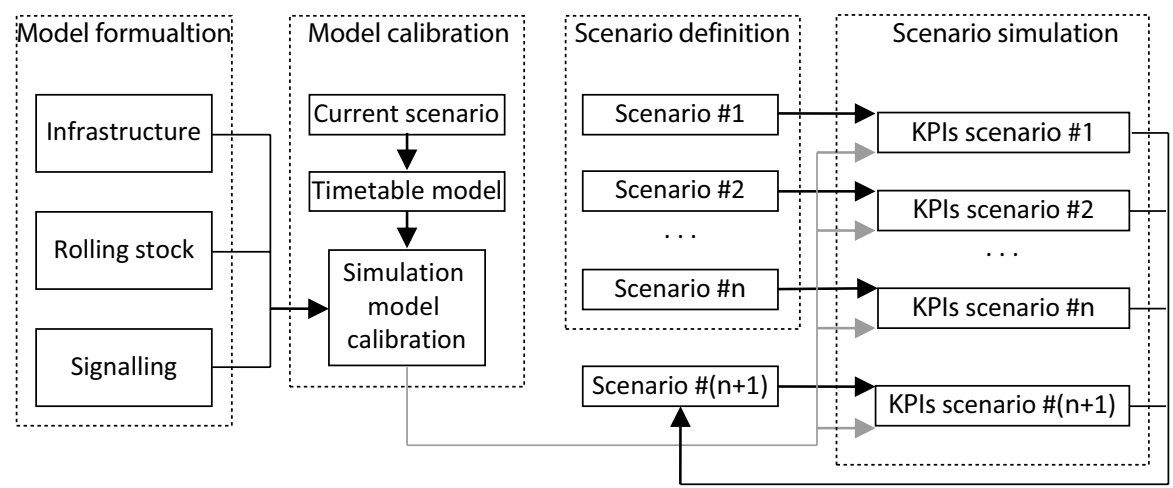

Figure 2: Flow chart of the proposed methodology.

The first step is to reproduce in a micro-simulation tool the infrastructure layout of the analysed line, which includes nodes, links, stations and signalling system functions, as well as available rolling stock and the adopted timetable. After that, the basic scenario is ready to be calibrated and validated, by comparing simulation results with the real planned service. After checking that the simulation model accurately reproduces the effective operational conditions of the line, a set of alternative scenarios have to be modelled.

In particular, key issues to be addressed for creating each simulation scenario are related to the assumptions on the implemented timetable structure and, consequently, on the identification of a feasible train-set circulation plan. Obviously, such two phases (i.e. timetabling process and definition of train-set circulation plan) are rather articulate since several variables are involved. As regards the timetable, different time rates need to be considered, i.e. running times, dwell times, inversion times, buffer times and layover times. Running times result by the simulation process, given the infrastructure layout and rolling stock performance, while dwell times (generally calculated as shown by [24]) are preliminary set as input simulation values. As regards the inversion times, they derive by the simulation process. In this respect, it is worth noting that, although our aim consists in estimating line capacity, rather than station capacity, the representation of terminal stations layout turns out to be fundamental in the estimation of inversion times and, therefore, in the cycle time to be considered in the timetabling process. Buffer times are generally set up during the design phase in order to address possible delays or, simply, eventual fluctuations which can occur during the service, given the stochasticity of the phenomenon being examined. Obviously, the lower the level of automation, the higher the relevance of the stochastic nature of the involved factors. With a high value of buffer times, the timetable presents greater flexibility and, thus, an increased chance of absorbing delays, avoiding their propagation; however, this could lead to an under-usage of system capacity. Therefore, it is necessary to identify the right balance between the use of railway capacity and the stability of timetable. For this reason, different values of buffer times have to be tested in the simulation procedure. Finally, the layover time is a time spent by the convoy at the terminus until the planned departure time dictated by the timetable and, hence, it derives from the link between train-sets and trip tasks identified in the following phase. Indeed, after having defined the timetable structure, a feasible set-circulation plan needs to be assumed on the basis of rolling stock availability. More in detail, as already said, the corresponding relationship between train-sets and trip tasks in the timetable has to be identified, according to specific routes and maintenance issues. 
After having built each scenario as explained above, the simulation can be run and key performance indexes (KPIs) can be computed. Finally, one or more design strategies which maximise network performance in terms of number of trains to be operated on the line are identified.

\section{REAL NETWORK APPLICATION}

In order to show the feasibility of the proposed method, it has been applied in the case of a real railway network which includes Cumana and Circumflegrea regional lines, operated by 'Ente Autonomo Volturno' company in Italy. Both involved lines have the same terminal stations (i.e. Montesanto and Torregaveta): Circumflegrea connects Naples city centre with the northwest area of the city and the towns in the Phleghrean Fields, and Cumana runs a southern route along the Bay of Naples. Moreover, an infrastructural improvement, consisting in building a short branch connecting the Soccavo station of Circumflegrea with the Edenlandia station of Cumana, has been approved by the Transport Ministry of the Italian government. Specifically, according to the project, the stretch, except for the connection with terminus stations (i.e. Soccavo and Edenlandia), will run underground and go through four stations, namely Monte Sant'Angelo, Parco San Paolo, Terracina and Giochi del Mediterraneo (Fig. 3).

In this context, the proposed simulation-based approach has been applied with the aim of performing a threshold analysis for identifying the maximum performance achievable on the network, thanks to this infrastructural improvement. Specifically, we adopt the commercial software OPENTRACK ${ }^{\circledR}$ [54].

Therefore, both Circumflegrea and Cumana lines, as well as the connection branch, need to be accurately modelled with related infrastructure layouts, signalling systems, rolling stock and timetable structures. Clearly, in a timetable design perspective, the layout of terminal/ connection stations needs to be accurately reproduced. Indeed, as already mentioned, such a layout determines inversion manoeuvres allowed and, therefore, planned inversion times which, in turn, affect the cycle time to be considered and the number of required convoys.

Tested scenarios have been built according to the design stages foreseen in the project of the branch. More in detail, the construction is planned to be implemented in three subsequent phases: (i) until Monte Sant'Angelo station, (ii) until Giochi del Mediterraneo station and (iii) until Edenlandia station (planned to be re-named as Kennedy station).

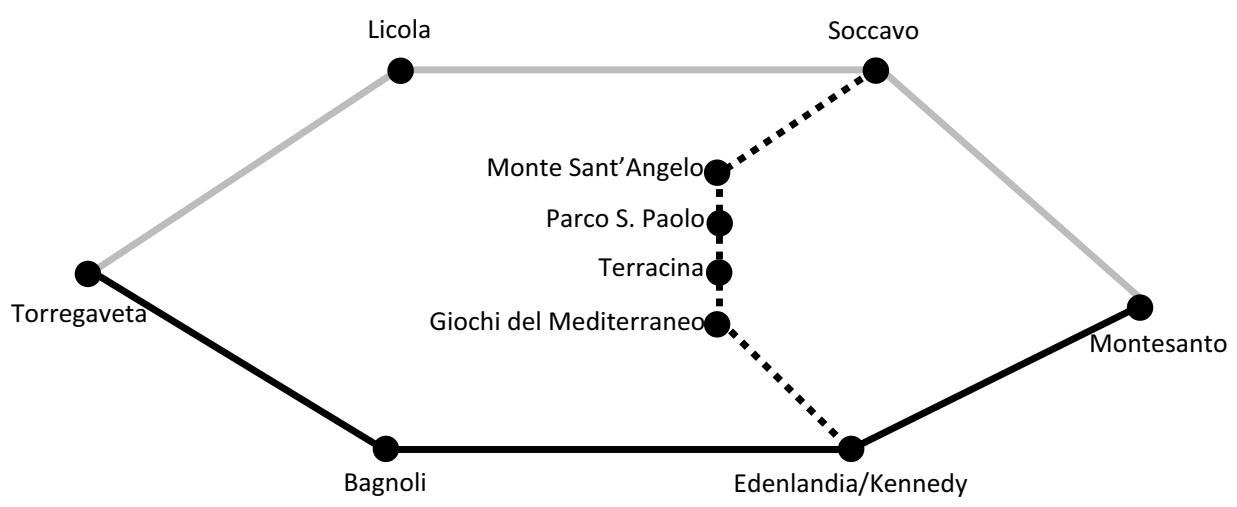

Cumana line

Circumflegrea line New line (branch)

Figure 3: The analysed network context. 
In this framework, a key factor to be addressed is represented by the connection scheme adopted for linking the branch with the Cumana line in the Edenlandia/Kennedy station. Specifically, two alternative schemes have been analysed: (i) indirect connection (i.e. terminus station of the branch and Edenlandia station of Cumana line coincide planimetrically but offset altimetrically); (ii) direct connection (i.e. the terminus station of the branch coincides with the Edenlandia station of Cumana line, since they are built at the same level). Clearly, a direct infrastructure connection allows a direct service, which becomes, instead, unfeasible in the second case. In particular, an indirect connection, beyond a different infrastructure design implies a two-side effect. On one hand, by an operational point of view, no interactions between trains on the branch and on the Cumana line occur; while, by a passengers' perspective, an interruption in the service occurs, since intermediate reloading is required for continuing the trip.

Moreover, according to the planned service, the infrastructure can be fully exploited or partially utilised. In particular, in the provided application, only combinations of infrastructure/ service which make full use of the available infrastructure are considered.

Therefore, the following configurations have been identified:

I. Soccavo-Monte Sant'Angelo (shuttle service);

II. Soccavo-Monte Sant'Angelo-Giochi del Mediterraneo (shuttle service);

III. Soccavo-Monte Sant'Angelo-Edenlandia/Kennedy (shuttle service in the case of indirect connection);

IV. Soccavo-Monte Sant'Angelo-Edenlandia/Kennedy (shuttle in the case of direct connection);

V. Montesanto-Soccavo-Monte Sant'Angelo (direct service via Circumflegrea);

VI. Montesanto-Soccavo-Monte Sant'Angelo-Giochi del Mediterraneo (direct service via Circumflegrea);

VII. Montesanto-Soccavo-Monte Sant'Angelo-Edenlandia/Kennedy (direct service via Circumflegrea in the case of indirect connection);

VIII. Montesanto-Soccavo-Monte Sant'Angelo-Edenlandia/Kennedy (direct service via Circumflegrea in the case of direct connection);

IX. Soccavo-Monte Sant'Angelo-Edenlandia/Kennedy-Montesanto (direct service via Cumana in the case of direct connection);

X. Circular line: Montesanto-Soccavo-Monte Sant'Angelo-Edenlandia/Kennedy-Montesanto.

Table 1: Timetable structures.

\begin{tabular}{llcc}
\hline Line & Services & \multicolumn{2}{c}{ Service headways [min] } \\
\cline { 3 - 4 } & & Scenario 2010 & Scenario 2019 \\
\hline Cumana & Montesanto-Torregaveta & 20 & 20 \\
& Montesanto-Bagnoli (simple service) & 20 & 0 \\
Circumflegrea & Montesanto-Bagnoli (cumulate service) & 10 & 20 \\
& Montesanto-Torregaveta & 40 & 3 runs per day* \\
& Montesanto-Licola (simple service) & 40 & 20 \\
& Montesanto-Licola (cumulate service) & 20 & 20 \\
\hline
\end{tabular}

"Degraded service for the reduction in public subsidies occurred in 2011. 


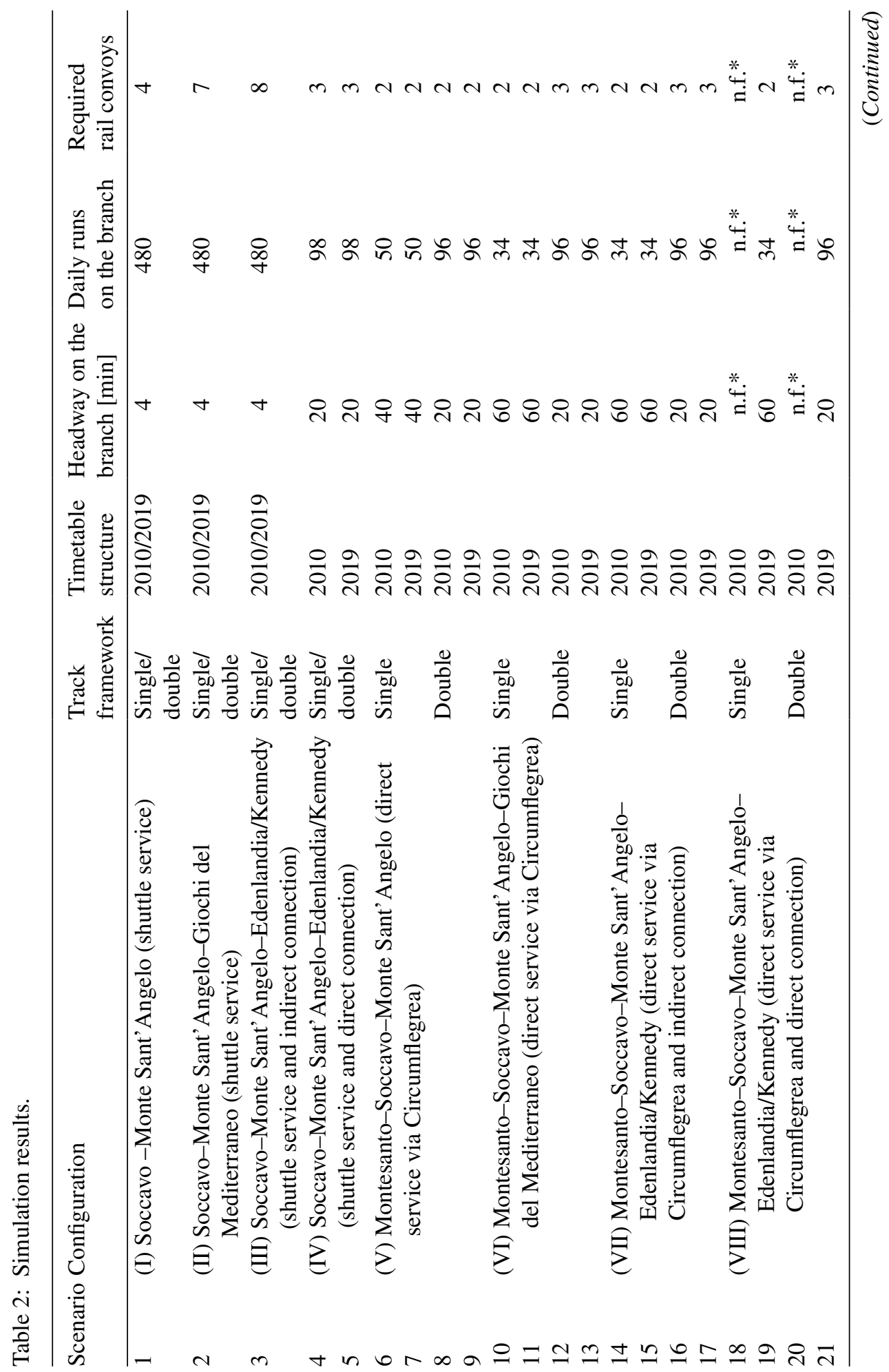




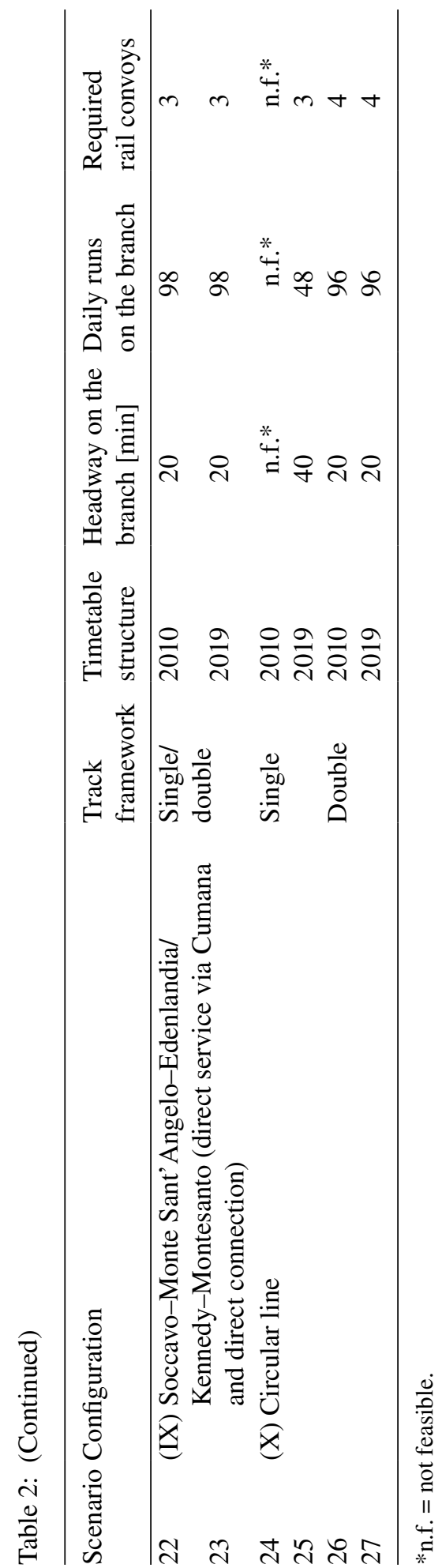


Such scenarios have been analysed by considering two different infrastructure layouts between Montesanto and Soccavo on the Circumflegrea line, that is, single-track (current condition) and double-track frameworks. The idea behind this to point out that such a singletrack section can represent a stringent limit for the improvement of line capacity.

Finally, in addition to the current timetable referred to 2019, which results strongly degraded because of the reduction in public subsidies occurred in 2011, the timetable dated 2010 has been simulated (see Table 1). The aim is to consider an operational service suitably optimised for the line, independent of exogenous reasons such as funding reductions.

Hence, by combining the 10 configurations identified above with the infrastructure layouts between Montesanto and Soccavo (i.e. single- and double-track frameworks) and the different adopted timetables (i.e. 2010 and 2019), a total of 27 scenarios have been simulated and compared on the basis of KPIs shown in Table 2. In particular, service headways, daily number of runs and number of convoys to be operated on the branch have been computed for each analysed scenario.

The alternatives maximising service frequency on the branch and the degree of infrastructure utilisation are highlighted in grey and, in particular, they are:

- Scenario 3 identifying a shuttle-service Soccavo-Edenlandia which fully exploits the branch and does not interfere with the existing lines (i.e. Circumflegrea and Cumana). This solution, by a passengers' point of view, presents a discomfort issue which is represented by the necessity of intermediate reloading in the terminal stations for continuing the trip on the existing lines;

- Scenarios 26 and 27 which differ exclusively for the timetable adopted on the existing lines. Such an option allows a duty fully exploiting the infrastructure and offers a service with no intermediate reloadings by means of a circular line. In addition, it generates synergies with the already existing runs on Circumflegera and Cumana lines, which are entirely to the benefit of users.

Moreover, the presence of three unfeasible scenarios (i.e. 18, 20 and 24) highlights the necessity of implementing doubling infrastructure measures as priority interventions.

\section{CONCLUSIONS AND RESEARCH PROSPECTS}

The article presents a simulation-based approach for performing a threshold analysis and, thus, providing the maximum number of trains to be operated on a line. The aim is to provide a decision support system for properly leading every successive evaluation. In particular, critical issues and strengths of such an approach have been identified and its feasibility has been shown by applying it to a real regional rail network. The methodology required an initial effort for suitably modelling infrastructure, signalling systems, rolling stock and timetable, but offers a proper basis for an accurate evaluation of effects due to the implementation of different intervention strategies. For example, in the case of the analysed context, the proposed method allowed identifying in the section Montesanto-Soccavo a bottleneck which could nullify any attempt of improving service quality. Moreover, the provided results allowed identifying a set of best measures to be implemented. In particular, in the light of the simulation outcome, authors propose to plan a service integrating the two alternatives identified (i.e. shuttle service and circular line), thus taking advantages from the synergies generated by the overlapping between these two configurations and, additionally, by the overlapping of them with existing runs on the Circumflegrea and Cumana lines (Fig. 4). In this way, on the 


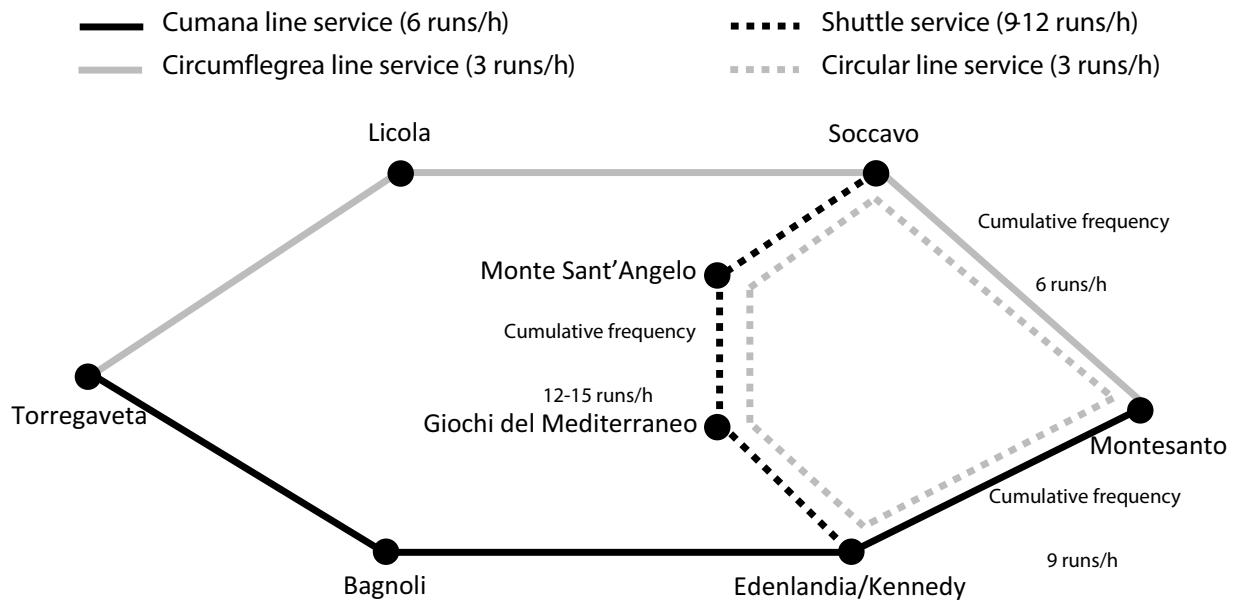

Figure 4: Integrated services.

branch, it is possible to reach a minimum headway of $4 \mathrm{~min}$, while, on the existing lines, it occurs that:

- Montesanto-Soccavo section reaches a cumulative frequency of 6 runs per hour. This means that the headway goes from the current $20 \mathrm{~min}$ to $10 \mathrm{~min}$, with a reduction in user waiting times of $50 \%$.

- Montesanto-Edenlandia section reaches a cumulative frequency of 9 runs per hour. This means that the headway goes from $10 \mathrm{~min}$ of the 2010 service to $6.7 \mathrm{~min}$, with a reduction in user waiting times of more than $33 \%$.

Moreover, in terms of user-generalised cost, by considering prudentially the current travel demand, the two above mentioned cases provide a reduction of, respectively, $156 \mathrm{M} €$ and $52 \mathrm{M} €$ per year, against a total investment of around $50 \mathrm{M} €$ required for the doubling of the section Montesanto-Soccavo.

What was said confirms the potentialities of the proposed method in supporting a cost-benefit analysis; however, as research prospects, the authors propose to perform additional tests in the case of other network contexts (e.g. high-speed lines) and non-ordinary operational conditions (i.e. disturbance/disruption scenarios), thus further validating the provided methodology.

\section{REFERENCES}

[1] Goverde, R.M.P., Punctuality of railway operations and timetable stability analysis. Ph.D. dissertation, Delft University of Technology, The Netherlands, 2005.

[2] Corman, F., D’Ariano, A. \& Hansen, I.A., Disruption handling in large railway networks. WIT Transactions on The Built Environment, 114, pp. 629-640, 2010.

[3] Cadarso, L., Marín, Á. \& Maróti, G., Recovery of disruptions in rapid transit networks. Transportation Research Part E, 53, pp. 15-33, 2013.

[4] Binder, S., Maknoon, Y. \& Bierlaire, M., Passenger-oriented railway disposition timetables in case of severe disruptions. Proceedings of the 15th Swiss Transport Research Conference (STRC 2015), Ascona, Switzerland, 2015. 
[5] Botte, M. \& D'Acierno, L., Dispatching and rescheduling tasks and their interactions with travel demand and the energy domain: Models and algorithms. Urban Rail Transit, 4(4), pp. 163-197, 2018.

[6] Kepaptsoglou, K. \& Karlaftis, M.G., A model for analyzing metro station platform conditions following a service disruption. Proceedings of the 13th International IEEE Annual Conference on Intelligent Transportation Systems (IEEE ITSC 2010), Funchal, Portugal, pp. 1789-1794, 2010.

[7] Cascetta, E., Cartenì, A. \& Henke, I., Stations quality, aesthetics and attractiveness of rail transport: empirical evidence and mathematical models. Ingegneria Ferroviaria, 69(4), pp. 307-324, 2014.

[8] Di Mauro, R., Botte, M. \& D’Acierno, L., An analytical methodology for extending passenger counts in a metro system. International Journal of Transport Development and Integration, 1(3), pp. 589-600, 2017.

[9] Xu, W., Zhao, P. \& Ning, L., A passenger-oriented model for train rescheduling on an urban rail transit line considering train capacity constraint. Mathematical Problems in Engineering, 2017, article no. 1010745, pp. 1-9, 2017.

[10] Zhu, Y. \& Goverde R.M.P., Dynamic passenger assignment during disruptions in railway systems. Proceedings of the 5th IEEE International Conference on Models and Technologies for Intelligent Transportation Systems (IEEE MT-ITS 2017), Naples, Italy, pp. 146-151, 2017.

[11] D'Acierno, L., Botte, M. \& Montella, B., Assumptions and simulation of passenger behaviour on rail platforms. International Journal of Transport Development and Integration, 2(2), pp. 123-135, 2018.

[12] Gallo, M., Improving equity of urban transit systems with the adoption of origin-destination based taxi fares. Socio-Economic Planning Sciences, 64, pp. 38-55, 2018.

[13] Kim, K.M., Kim, K.T. \& Han, M.S., A model and approaches for synchronized energy saving in timetabling. Proceedings of 9th World Congress on Railway Research (WCRR 2011), Lille, France, 2011.

[14] Chevrier, R., Pellegrini, P. \& Rodriguez, J., Energy saving in railway timetabling: A bi-objective evolutionary approach for computing alternative running times. Transportation Research Part C, 37, pp. 20-41, 2013.

[15] D’Acierno, L., Botte, M., Gallo, M. \& Montella, B., Defining reserve times for metro systems: An analytical approach. Journal of Advanced Transportation, 2018, art. no. 5983250, pp. 1-15, 2018.

[16] D'Acierno, L. \& Botte, M., Passengers' satisfaction in the case of energy-saving strategies: A rail system application. Proceedings of the 18th IEEE International Conference on Environment and Electrical Engineering (IEEE EEEIC 2018) and 2nd Industrial and Commercial Power Systems Europe (I\&CPS 2018), Palermo, Italy, pp. 795-799, 2018.

[17] D'Acierno, L. \& Botte, M., A passenger-oriented optimization model for implementing energy-saving strategies in railway contexts. Energies, 11(11), art. no. 2946, pp. 1-25, 2018.

[18] Cartenì, A., Accessibility indicators for freight transport terminals. Arabian Journal for Science and Engineering, 39(11), pp. 7647-7660, 2014.

[19] Cartenì, A., Urban sustainable mobility. Part 1: Rationality in transport planning. Transport Problems, 9(4), pp. 39-48, 2014.

[20] Cartenì, A., Urban sustainable mobility. Part 2: Simulation models and impacts estimation. Transport Problems, 10(1), pp. 5-16, 2015. 
[21] Gallo, M., The impact of urban transit systems on property values: A model and some evidences from the city of Naples. Journal of Advanced Transportation, 2018, art. no. 1767149, pp. 1-22, 2018.

[22] Cacchiani, V., Huisman, D., Kidd, M., Kroon, L., Toth, P., Veelenturf, L. \& Wagenaar, J., An overview of recovery models and algorithms for real-time railway rescheduling. Transportation Research Part B, 63, pp. 15-37, 2014.

[23] Guglielminetti, P., Piccioni, C., Fusco, G., Licciardello, R. \& Musso, A., Single wagonload traffic in Europe: Challenges, prospects and policy options. Ingegneria Ferroviaria, 70(11), pp. 927-948, 2015.

[24] D’Acierno, L., Botte, M., Placido, A., Caropreso, C. \& Montella, B., Methodology for determining dwell times consistent with passenger flows in the case of metro services. Urban Rail Transit, 3(2), pp. 73-89, 2017.

[25] Miyatake, M. \& Matsuda, K., Energy saving speed and charge/discharge control of a railway vehicle with on-board energy storage by means of an optimization model. IEEJ Transactions on Electrical and Electronic Engineering, 4(6), pp. 771-778, 2009.

[26]Albrecht, A., Howlett, P., Pudney, P. \& Vu, X., Energy-efficient train control: from local convexity to global optimization and uniqueness. Automatica, 49(10), pp. 3072-3078, 2013.

[27] De Martinis, V., Weidmann, U. \& Gallo, M., Towards a simulation-based framework for evaluating energy-efficient solutions in train operation, WIT Transactions on the Built Environment, 135, pp. 721-732, 2014.

[28] D’Acierno, L., Botte, M. \& Montella, B., An analytical approach for determining reserve times on metro systems. Proceedings of the 17th IEEE International Conference on Environment and Electrical Engineering (IEEE EEEIC 2017) and 1st Industrial and Commercial Power Systems Europe (I\&CPS 2017), Milan, Italy, pp. 722-727, 2017.

[29] Cornic, D., Efficient recovery of braking energy through a reversible dc substation. Proceedings of Electrical Systems for Aircraft, Railway and Ship Propulsion (ESARS 2010), Bologna, Italy, 2010.

[30] Ibaiondo, H. \& Romo, A., Kinetic energy recovery on railway systems with feedback to the grid. Proceedings of the 14th International Power Electronics and Motion Control Conference (EPE-PEMC 2010), Ohrid, Macedonia, pp. 94-97, 2010.

[31] Domínguez, M., Fernández-Cardador, A., Cucala, A.P. \& Pecharromán, R.R., Energy savings in metropolitan railway substations through regenerative energy recovery and optimal design of ATO speed profiles. IEEE Transactions on Automation Science and Engineering, 9(3), pp. 496-504, 2012.

[32] Prencipe, F.P. \& Petrelli, M., Analytical methods and simulation approaches for determining the capacity of the Rome-Florence "Direttissima" line. Ingegneria Ferroviaria, 73(7-8), pp. 599-633, 2018.

[33] International Union of Railways (UIC), UIC Code 406: Capacity. 2nd ed., 2013.

[34] Schwanhäusser, W., Die Bemessung der Pufferzeiten im Fahrplangefüge der Eisenbahn, Ph.D. Dissertation, RWTH Aachen University, Germany, 1974.

[35] Bonora, G. \& Giuliani, L., I criteri di calcolo di potenzialità delle linee ferroviarie. Ingegneria Ferroviaria, 37(7), 1982.

[36] International Union of Railways (UIC), UIC Leaflet 405-1: Method to be used for the determination of the capacity of Lines, 1983.

[37] Rete Ferroviaria Italiana - RFI (Italian National Railway Infrastructure Manager), Metodi di calcolo della capacità delle linee ferroviarie, Technical Report, 2011.

[38] Schultze, K., Gast, I. \& Schwanhäusser, W., Sls plus - Einführung, Koblenz, Berlin, Germany, 2015. 
[39] Gonzalez, J., Rodriguez, C., Blanquer, J., Mera, J.M., Castellote, E. \& Santos, R., Increase of metro line capacity by optimisation of track circuit length and location: In a distance to go system. Journal of Advanced Transportation, 44(2), pp. 53-71, 2010.

[40] Lindfeldt, A., Railway capacity analysis: Methods for simulation and evaluation of timetables, delays and infrastructure. Ph.D. Dissertation, KTH Royal Institute of Technology, Sweden, 2015.

[41] Middelkoop, D. \& Bouwman, M., SIMONE: Large scale train network simulations. Proceedings of the 2001 Winter Simulation Conference, Piscataway (NJ), USA, pp. 1042-1047, 2001.

[42] Sewcyk, B. \& Kettner, M., Network Evaluation Model NEMO. Proceedings of the 5th World Congress on Rail Research (WCRR 2001), Cologne, Germany, 2001.

[43] Marinov, M. \& Viegas, J., A mesoscopic simulation modelling methodology for analyzing and evaluating freight train operations in a rail network. Simulation Modelling Practice and Theory, 19(1), pp. 516-539, 2011.

[44] De Fabris, S., Longo, G., Medeossi, G. \& Pesenti, R., Automatic generation of railway timetables based on a mesoscopic infrastructure model. Journal of Rail Transport Planning \& Management, 4(1-2), pp. 2-13, 2014.

[45] Radtke, A. \& Bendfeldt, J., Handling of railway operation problems with RailSys. Proceedings of the 5th World Congress on Rail Research (WCRR 2001), Cologne, Germany, 2001.

[46] Quaglietta, E., A Microscopic Simulation Model for supporting the design of railway systems: development and applications. Ph.D. dissertation, University of Naples Federico II, Italy, 2011.

[47] Quaglietta, E., Punzo, V., Montella, B., Nardone, R. \& Mazzocca, N., Towards a hybrid mesoscopic-microscopic railway simulation model. Proceedings of the 2nd IEEE International Conference on Models and Technologies for Intelligent Transportation Systems (IEEE MT-ITS 2011), Leuven, Belgium, 2011.

[48] Botte, M., Di Salvo, C., Placido, A., Montella, B. \& D’Acierno, L., A Neighbourhood Search Algorithm for determining optimal intervention strategies in the case of metro system failures. International Journal of Transport Development and Integration, 1(1), pp. 63-73, 2017.

[49] Quaglietta, E., Corman, F. \& Goverde, R.M.P., Impact of a stochastic and dynamic setting on the stability of railway dispatching solutions. Proceedings of the 16th International IEEE Conference on Intelligent Transportation Systems (IEEE ITSC 2013), The Hague, The Netherlands, pp. 1035-1040, 2013.

[50] Quaglietta, E. \& Punzo, V., Supporting the design of railway systems by means of a Sobol variance-based sensitivity analysis. Transportation Research Part C, 34, pp. 38-54, 2013.

[51] D’Acierno, L., Placido, A., Botte, M., Gallo, M. \& Montella, B. Defining robust recovery solutions for preserving service quality during rail/metro systems failure. International Journal of Supply and Operations Management, 3(3), pp. 1351-1372, 2016.

[52] D'Acierno, L., Placido, A., Botte, M. \& Montella B., A methodological approach for managing rail disruptions with different perspectives. International Journal of Mathematical Models and Methods in Applied Sciences, 10, pp. 80-86, 2016.

[53] Jacobs, J. Reducing delays by means of computer-aided 'on-the-spot' rescheduling, WIT Transactions on The Built Environment, 74, pp. 603-612, 2004.

[54] Nash, A. \& Huerlimann, D., Railroad simulation using OpenTrack. WIT Transactions on The Built Environment, 74, pp. 45-54, 2004. 